\title{
PENGARUH PEMBELAJARAN KOOPERATIF TIPE TGT DAN GAYA BELAJAR MODEL VARK TERHADAP HASIL BELAJAR KIMIA SEKOLAH PADA MAHASISWA PROGRAM STUDI PENDIDIKAN KIMIA
}

\author{
Tuti Kurniati ${ }^{1}$, Rizmahardian Ashari Kurniawan ${ }^{1}$ \\ ${ }^{1}$ Fakultas Keguruan dan Ilmu Pendidikan, Universitas Muhammadiyah Pontianak \\ Jl. A. Yani no. 111 \\ E-mail: kurniati_tuti@ymail.com
}

\begin{abstract}
This research aims to investigate the effects of Teams Games Tournament (TGT) cooperative technique and VARK learning style student for learning School of Chemistry. This research using quasy experiment with 2 independent variables, TGT cooperative technique and VARK learning style, and 1 dependent variable, learning outcome. The subjects are students of Education of Chemistry in Muhammadiyah University. The instruments were test, documentation, and questioner. The hypothesis test is 0,00 so it achieved a significant learning outcome in experimental group class. The result of effect size show 1,415, categorized in the high category and give the significant learning outcome.
\end{abstract}

\section{Keywords: School of Chemistry, Learning Style, Teams Games Tournament (TGT)}

Pendidikan di Indonesia saat ini masih memiliki kualitas yang rendah. Hal ini terlihat masih kurangnya daya saing di dunia kerja. Padahal pendidikan merupakan ujung tombak dalam pembangunan masa depan suatu bangsa. Menurut undangundang Republik Indonesia Nomor 20 Tahun 2003 tentang Sistem Pendidikan Nasional, pendidikan adalah usaha sadar dan terencana untuk mewujudkan suasana belajar dan proses pembelajaran agar peserta didik secara aktif mengembangkan potensi dirinya untuk memiliki kekuatan spiritual keagamaan, pengendalian diri, kepribadian, kecerdasan, akhlak mulia serta keterampilan yang diperlukan dirinya, masyarakat, bangsa, dan negara.

Terwujudnya suasana belajar dan proses pembelajaran yang optimal perlu direncanakan dan dibangun sedemikian rupa oleh guru yang bertindak sebagai motivator dan fasilitator. Sehingga model pembelajaran yang digunakan tepat dan para peserta didik memperoleh kesempatan untuk berinteraksi satu sama lain.

Kimia Sekolah merupakan salah satu mata kuliah yang esensial bagi mahasiswa program studi Pendidikan Kimia. Konsep yang dipelajari dalam Kimia Sekolah menjadi dasar bagi para mahasiswa sebagai calon guru untuk 
mengajarkan konsep kimia pada siswa di sekolah, sehingga pada saat mengajar tidak terjadi salah konsep pada saat menyampaikan materi. Kesalahan konsep yang terjadi pada saat menyampaikan materi dapat berakibat pada rendahnya hasil belajar siswa dan membangun asumsi bahwa kimia itu sulit. Akibatnya kimia dapat menjadi mata pelajaran yang tidak disenangi oleh siswa. Namun, hasil belajar yang diperoleh mahasiswa pada mata kuliah Kimia Sekolah masih tergolong rendah. Rendahnya hasil belajar mahasiswa pada mata kuliah Kimia Sekolah dikarenakan kurangnya variasi dalam pembelajaran. Sehingga mahasiswa merasa bosan pada materi yang disampaikan dan pembelajaran di kelas menjadi tidak aktif.

$$
\text { Penggunaan model }
$$

pembelajaran yang bervariasi dapat membantu mahasiswa untuk dapat ikut serta dalam pembelajaran. Sehingga dapat menciptakan suasana pembelajaran yang aktif dan meningkatkan hasil belajar mahasiswa. Model pembelajaran kooperatif dianggap cocok diterapkan dalam pendidikan di Indonesia karena sesuai dengan budaya bangsa Indonesia yang menjunjung tinggi nilai gotong royong (Buchari, 2008). Model pembelajaran kooperatif memberi kesempatan kepada siswa untuk berinteraksi secara terbuka dan memberikan suasana yang menyenangkan sehingga akan tercipta adanya saling ketergantungan positif, interaksi tatap muka, penilaian individual, dan dapat mengembangkan hubungan antar kelompok, penerimaan terhadap teman sekelas yang lemah akademiknya, serta meningkatkan rasa harga diri (Desstya, dkk., 2012).

Terdapat beberapa model pembelajaran kooperatif yang inovatif, salah satunya dengan menggunakan model pembelajaran kooperatif tipe Teams Games Tournament (TGT). Dengan pemberian tipe TGT pendidik memberikan teknik pada proses belajar mengajar dengan mengadakan turnamen-turnamen kecil (Ibrahim, 2011). Model pembelajaran TGT terdiri dari lima langkah yaitu; tahap penyajian kelas, belajar dalam kelompok, permainan, pertandingan dan penghargaan kelompok (Slavin, 2008).

Selain model pembelajaran, faktor lain yang menentukan hasil belajar adalah gaya belajar peserta didik. Penerapan model pembelajaran yang sesuai dengan gaya belajar peserta didik akan mendorong pencapaian hasil belajar yang maksimal. Model gaya belajar yang umum digunakan yaitu Holland, David Kolb, Dunn dan Dunn, DePorter Hernacki (model VAK) dan Fleaming (VARK) (Ghufron, 2010; Hasrul, 2009; Hawk, 2007).

Memperhatikan kondisi tersebut, peneliti tertarik untuk memfokuskan pada pengaruh model pembelajaran kooperatif tipe TGT dan gaya belajar model VARK terhadap hasil belajar kimia sekolah pada mahasiswa Program Studi Pendidikan Kimia Universitas Muhammadiyah Pontianak.

\section{METODE}

Metode yang digunakan dalam penelitian ini adalah metode eksperimen. Pada penelitian ini menggunakan Quasi Experiment 
yaitu, penelitian yang mendekati percobaan sungguhan dimana tidak mungkin mengadakan kontrol atau manipulasi semua variabel yang relevan. Harus ada kompromi dalam menentukan validitas internal dan eksternal sesuai dengan batasanbatasan yang ada (Nazir, 2005). Desain eksperimen yang digunakan adalah One-Group-Pretest-Posttest dengan satu kelas yang mendapatkan treatment tanpa kelas kontrol sebagai pembanding. Desain penelitian tersebut menurut Arikunto (2010: 124) dapat dilihat pada Tabel 1.

Tabel 1. Desain penelitian

\begin{tabular}{cccc}
\hline Kelas & $\begin{array}{c}\text { Pre } \\
\text { test }\end{array}$ & $\begin{array}{c}\text { Treat } \\
\text { ment }\end{array}$ & $\begin{array}{c}\text { Post } \\
\text { test }\end{array}$ \\
\hline Eksperimen & $\mathrm{O} 1$ & $\mathrm{X}$ & $\mathrm{O} 2$ \\
\hline
\end{tabular}

Keterangan :

$\mathrm{O} 1=$ Pemberian pretest dilakukan untuk mengetahui kemampuan awal siswa

$\mathrm{X}=$ Pemberian treatment, berupa model pembelajaran kooperatif tipe TGT

$\mathrm{O} 2=$ Pemberian posttest untuk mengukur variabel terikat setelah perlakuan

Penelitian ini dilaksanakan di

Universitas Muhammadiyah Pontianak. Waktu penelitian dilaksanakan selama dua bulan. Subjek penelitian ini adalah mahasiswa semester V Program Studi Pendidikan Kimia FKIP Universitas Muhammadiyah Pontianak sebanyak 34 orang.

Variabel penelitian ini terdiri dari variabel independen yaitu penggunaan model pembelajaran kooperatif tipe TGT dan gaya belajar model VARK yaitu gaya belajar visual, aural, read-write dan kinestethic yang dikembangkan oleh (Flemming \& Mills, 1992) dan variabel dependen yaitu hasil belajar mahasiswa dalam pembelajaran kimia sekolah. Instrumen yang digunakan dalam penelitian ini adalah tes hasil belajar dan tes gaya belajar model VARK berupa kuesioner.

Teknik pengumpulan data yang digunakan dalam penelitian ini adalah metode tes, komunikasi tidak langsung, dan dokumentasi. Teknik analisis data yang digunakan berupa uji normalitas data, uji homogenitas data, uji hipotesis dan perhitungan effect size. Uji normalitas digunakan untuk mengetahui sampel dari populasi data berdistribusi normal atau tidak. Uji normalitas yang digunakan dalam penelitian ini adalah uji Kolmogorov-Smirnov. Uji homogenitas menggunakan uji F. Uji homogenitas dilakukan pada skor hasil pretest dan posttest. Jika nilai signifikansi > 0,05 maka dapat varian data dua atau lebih adalah sama atau homogen, sedangkan jika signifikansi $<0,05$ maka varian data dua atau lebih tidak sama atau tidak homogen. Uji hipotesis dilakukan dengan program SPSS yaitu menggunakan uji t berpasangan (Two Paired Samples Test) untuk uji dua sisi (two tailed atau two sides). Uji hipotesis komparasi antara dua variabel yang berbeda, yaitu antara hasil belajar siswa sebelum menggunakan tipe Teams Games Tournament (TGT) dan gaya belajar model VARK dengan hasil belajar siswa setelah menggunakan tipe TGT dan gaya belajar model VARK. Perhitungan effect size untuk mengetahui berapa besar pengaruh model pembelajaran 
kooperatif tipe TGT terhadap hasil belajar mahasiswa semester V. Adapun rumus effect size dapat dilihat pada persamaan berikut :

$$
\mathrm{ES}=\frac{X e-X c}{S c}
$$

Keterangan :

$\mathrm{ES}=$ Effect Size

$\mathrm{Xe}=$ Rata-rata hitung posttest

$\mathrm{Xc}=$ Rata-rata hitung pretest

$\mathrm{Sc}=$ Standar deviasi

\section{HASIL DAN PEMBAHASAN}

Penelitian dengan penerapan model pembelajaran kooperatif tipe TGT dan gaya belajar model VARK merupakan penelitian eksperimen yang dilakukan di Universitas
Muhammadiyah Pontianak pada mahasiswa semester V Program Studi Pendidikan Kimia FKIP yang berjumlah sebanyak 34 orang, tahun ajaran 2015/2016. Data hasil penelitian berupa nilai hasil belajar dan kuisioner berupa angket yang diberikan kepada responden. Selanjutnya data hasil belajar tersebut diolah untuk diketahui normalitas, homogenitas dan uji hipotesisnya dengan menggunakan SPSS.

\section{Hasil Belajar Pretest-Posttest}

Hasil belajar ini diperoleh dari nilai prestest dan posttest mahasiswa yang dilakukan dengan dua kali pertemuan. Hasil belajar yang diperoleh dapat dilihat pada Tabel 2 dan Tabel 3.

Tabel 2. Persentase ketuntasan pretest dan posttest pertemuan I

\begin{tabular}{|c|c|c|c|c|c|}
\hline & \multirow{2}{*}{$\begin{array}{c}\text { Jumlah } \\
\text { siswa }\end{array}$} & \multicolumn{2}{|c|}{ Persentase (\%) } & \multirow{2}{*}{$\begin{array}{l}\text { Nilai } \\
\text { rata- } \\
\text { rata }\end{array}$} & \multirow{2}{*}{$\begin{array}{l}\text { Standal } \\
\text { deviasi }\end{array}$} \\
\hline & & Tuntas & $\begin{array}{l}\text { Tidak } \\
\text { tuntas }\end{array}$ & & \\
\hline Pretest & 34 & 0 & 100 & 34 & 15,52 \\
\hline Posttest & 34 & 32 & 68 & 60,4 & \\
\hline
\end{tabular}

Tabel 3. Persentase ketuntasan pretest dan posttest pertemuan II

\begin{tabular}{|c|c|c|c|c|c|}
\hline & \multirow{2}{*}{$\begin{array}{c}\text { Jumlah } \\
\text { siswa }\end{array}$} & \multicolumn{2}{|c|}{ Persentase (\%) } & \multirow{2}{*}{$\begin{array}{l}\text { Nilai } \\
\text { rata- } \\
\text { rata }\end{array}$} & \multirow{2}{*}{$\begin{array}{l}\text { Standal } \\
\text { deviasi }\end{array}$} \\
\hline & & Tuntas & $\begin{array}{l}\text { Tidak } \\
\text { tuntas }\end{array}$ & & \\
\hline Pretest & 34 & 35 & 65 & 57 & 21,22 \\
\hline Posttest & 34 & 76 & 24 & 82 & \\
\hline
\end{tabular}

Tabel 2 menunjukkan nilai rata-rata pretest mahasiswa pada pertemuan I sebesar $34 \%$ dan nilai rata-rata posttest mahasiswa sebesar $60,4 \%$. Berdasarkan hasil pretest diketahui sebanyak 0 mahasiswa (sebesar 0\%) yang mencapai KKM, sedangkan pada hasil posttest sebanyak 11 mahasiswa (32\%) tuntas mencapai KKM.
Tabel 3 menunjukkan nilai rata-rata pretest mahasiswa pada pertemuan II sebesar $57 \%$ dan nilai rata-rata posttest mahasiswa sebesar $82 \%$. Diketahui dari hasil pretest sebanyak 12 mahasiswa (35\%) mencapai KKM, dan pada hasil posttest sebanyak 26 mahasiswa $(76 \%)$ tuntas mencapai KKM. 


\section{Analisis Data Pertemuan I}

\section{a. Uji Normalitas Data}

Hasil uji Kolmogorov-

Smirnov menunjukkan bahwa nilai normalitas pretest pada pertemuan I adalah 0,136. Nilai tersebut lebih besar dari nilai $\alpha(0,05)$ maka data dapat dikatakan terdistribusi normal. Sedangkan nilai normalitas posttest pada pertemuan I adalah 0,082. Nilai tersebut lebih besar dari nilai $\alpha(0,05)$ maka data dikatakan terdistribusi normal.

\section{b. Uji Homogenitas Data}

Pengujian statistik homogenitas data dengan taraf signifikan $(\alpha)=0,05$ diperoleh hasil sebesar 0,184. Nilai tersebut lebih besar dari nilai $\alpha(0,05)$ artinya sampel dalam penelitian ini berasal dari populasi yang memiliki variansi yang homogen.

\section{c. Uji Hipotesis Penelitian}

Berdasarkan hasil perhitungan normalitas data dan homogenitas varians didapatkan bahwa data terdistribusi normal dan tidak homogen. Pengujian ini bertujuan untuk mengetahui apakah terdapat perbedaan yang signifikan antara hasil belajar pada mahasiswa kelas eksperimen. Pengujian statistik menggunakan statistik uji-t dengan taraf signifikan $\alpha=0,05$, diperoleh hasil 0,0000. Berdasarkan kriteria pengujian $\mathrm{H}_{0}$ ditolak dan $\mathrm{H}_{\mathrm{a}}$ diterima yang berarti terdapat perbedaan yang signifikan pada hasil belajar mahasiswa pada kelas eksperimen yang menggunakan model pembelajaran kooperatif tipe TGT.

\section{Analisis Data Pertemuan II}

a. Uji Normalitas data

Hasil uji kolmogorovSmirnov menunjukkan bahwa nilai normalitas pretest pada pertemuan II adalah 0,150. Nilai tersebut lebih besar dari nilai $\alpha(0,05)$ maka data dapat dikatakan terdistribusi normal. Sedangkan nilai normalitas posttest pada pertemuan II adalah 0,010. Nilai tersebut lebih kecil dari nilai $\alpha(0,05)$ maka data dikatakan tidak terdistribusi normal.

\section{b. Uji Hipotesis Penelitian}

Berdasarkan hasil

perhitungan normalitas data dan homogenitas varians didapatkan bahwa salah satu data tidak terdistribusi normal maka dilanjutkan dengan uji statistik non parametrik menggunakan uji Wilxocon. Pengujian statistik menggunakan uji Wilxocon dengan taraf signifikan $\alpha=0,05$, diperoleh hasil 0,0000 . Berdasarkan kriteria pengujian $\mathrm{H}_{0}$ ditolak dan $\mathrm{H}_{\mathrm{a}}$ diterima yang berarti terdapat perbedaan yang signifikan pada hasil belajar mahasiswa pada kelas eksperimen yang menggunakan model pembelajaran kooperatif tipe TGT.

\section{Kecenderungan Gaya belajar pada Mahasiswa}

Penentuan gaya belajar yang dominan ada pada mahasiswa yaitu dengan diberikan kuisioner gaya belajar model VARK test edisi 7.1. Adapun gambaran gaya belajar mahasiswa semester V FKIP Pendidikan Kimia Universitas Muhammadiyah Pontianak dapat dilihat pada Tabel 4. 
Tabel 4. Gaya belajar mahasiswa semester V.

\begin{tabular}{clcc}
\hline No & \multicolumn{1}{c}{ Gaya Belajar } & $\begin{array}{c}\text { Jumlah } \\
\text { Siswa }\end{array}$ & $\%$ \\
\hline 1. & Aural & 2 & 5,8 \\
2. & Visual & 1 & 3,0 \\
3. & Kinesthetic & 15 & 44,2 \\
4. & Kinesthetic-Aural & 2 & 5,8 \\
5. & Visual-Read/Write & 1 & 3,0 \\
6. & Aural-Kinesthetic & 1 & 3,0 \\
7. & Read/Write-Kinesthetic & 2 & 5,8 \\
8. & Aural-Read/Write-Kinesthetic & 5 & 14,7 \\
9. & Visual-Aural-Read/Write-Kinesthetic & 5 & 14,7 \\
\hline
\end{tabular}

Berdasarkan Tabel 4, gaya belajar yang ditemukan pada mahasiswa semester V FKIP Program Studi Pendidikan Kimia adalah unimodal dan multimodal. Gaya belajar unimodal adalah gaya belajar tunggal yang terdiri dari hanya salah satu tipe dari tipe gaya belajar VARK. Sedangkan gaya belajar multimodal adalah gaya belajar yang merupakan kombinasi lebih dari satu tipe gaya belajar. Gaya belajar yang paling banyak digunakan adalah gaya belajar unimodal yaitu kinesthetic, dengan jumlah sebesar 44,2\%.

Tahap awal penelitian adalah menyiapkan instrumen untuk mengumpulkan data berupa tes hasil belajar dan kuisioner gaya belajar VARK edisi 7.1. Sebelum digunakan pada penelitian, terlebih dahulu tes hasil belajar divalidasi untuk mengetahui apakah tes hasil belajar layak digunakan untuk mengukur hasil belajar siswa.

Penelitian ini menggunakan model pembelajaran kooperatif tipe TGT pada materi asam basa dan larutan penyangga. Dalam pembelajaran dengan menggunakan model pembelajaran kooperatif tipe
TGT siswa dibentuk dalam beberapa kelompok, setelah dibentuk dalam beberapa kelompok siswa dibagi lagi dalam meja turnamen. Tujuan dibaginya siswa dalam meja turnamen adalah untuk melakukan turnamen yang merupakan keunggulan dari metode kooperatif tipe TGT. Pengelompokkan ini bertujuan untuk menciptakan pendekatan pembelajaran secara efektif yang mengintegrasikan keterampilan sosial bermuatan akademis (Nopiyanita, dkk., 2013). Dengan game yang dilakukan dalam pembelajaran ini diharapkan dapat membangkitkan minat siswa dalam belajar sehingga akhirnya mampu meningkatkan hasil belajar siswa. Setelah diberi perlakuan, kelas eksperimen diberikan posttest yang bertujuan untuk mengetahui hasil belajar siswa setelah diberi perlakuan. Perlakuan dengan model pembelajaran kooperatif tipe TGT dilakukan 2 kali pertemuan. Pertemuan pertama pada materi asam basa, dan pertemuan kedua pada materi larutan penyangga. Dari kedua posttest yang dilakukan diperoleh hasil bahwa $\mathrm{H}_{0}$ ditolak dan $\mathrm{H}_{\mathrm{a}}$ 
diterima, menunjukkan bahwa terdapat perbedaan hasil belajar pada kelas eksperimen yang menggunakan model pembelajaran kooperatif tipe TGT.

\begin{tabular}{lrr}
\multicolumn{2}{c}{ Perhitungan } & effect size \\
digunakan untuk & mengetahui \\
pengaruh model & pembelajaran \\
kooperatif tipe TGT.
\end{tabular}

Tabel 5. Standar deviasi dan effect

\begin{tabular}{llcc}
\multicolumn{4}{c}{ size } \\
\hline No & $\begin{array}{c}\text { Hasil } \\
\text { Analisis }\end{array}$ & $\begin{array}{c}\text { Pertemuan } \\
\text { I }\end{array}$ & $\begin{array}{c}\text { Pertemuan } \\
\text { II }\end{array}$ \\
\hline 1 & $\begin{array}{l}\text { Standar } \\
\text { Deviasi } \\
\text { Effect } \\
\text { Size }\end{array}$ & 15,52 & 21,22 \\
& 1,69 & 1,14 \\
\hline
\end{tabular}

Nilai standar deviasi pertemuan I sebesar 15,52 menghasilkan effect size sebesar 1,69. Sedangkan standar deviasi pertemuan II sebesar 21,22 menghasilkan effect size sebesar 1,14. Jika dirata-ratakan maka nilai effect size dari dua kali perlakuan tersebut adalah 1,415. Hal ini menunjukkan bahwa effect size masuk dalam kategori tinggi dan memberikan pengaruh yang tinggi terhadap peningkatan hasil belajar siswa. Besarnya pengaruh tersebut merujuk pada tabel $\mathrm{Z}$ diperoleh nilai sebesar $42,07 \%$.

Hasil penelitian ini sesuai dengan hasil penelitian yang dilakukan oleh Desstya, dkk (2012) bahwa terdapat pengaruh yang siginifikan pembelajaran kimia metode TGT menggunakan media animasi dan kartu terhadap prestasi belajar siswa dengan nilai rata-rata sebesar 66,32 pada kelas media animasi dan 60,13 pada kelas media kartu.
Hasil tersebut menunjukkan bahwa pembelajaran kooperatif tipe TGT mampu membuat siswa menjadi aktif dalam bekerjasama dalam kelompok, karena siswa tidak merasa malu untuk bertanya dengan teman dalam satu kelompok. Selain itu melatih siswa untuk berpikir dengan cepat dalam menjawab pertanyaan yang diajukan pada saat game berlangsung.

Pada penelitian ini diberikan kuesioner untuk mengetahui gaya belajar pada mahasiswa. Hasil penelitian menunjukkan bahwa 44,2\% mahasiswa menggunakan satu jenis model gaya belajar. Gaya belajar yang paling banyak digunakan adalah model kinesthetic. Perilaku siswa dengan gaya belajar kinesthetic yaitu mencatat teks kembali, membaca catatan, merangkum diagram, grafik, tabel, atau apapun ke dalam laporan dan mengubah reaksi, tindakan grafik dan diagram ke word (Flemming \& Mills, 1992)

Pada pembelajaran model kooperatif tipe TGT materi asam basa dan larutan penyangga, siswa dengan gaya belajar kinesthetic mampu belajar dengan baik karena dilibatkan secara fisik dalam pembelajaran. Menurut Desstya (2012) dalam proses pembelajaran, siswa yang memiliki gaya belajar kinestetik dapat diketahui dari gerakan anggota tubuhnya. Mahasiswa dengan gaya belajar kinesthetic akan mengalami kesulitan dalam belajar apabila belajar dalam keadaan diam atau tanpa melibatkan aktivitas (pergerakan) sehingga siswa kinesthetic seringkali tertinggal dalam pembelajaran (Nufida, 2015). Oleh karena itu, gaya belajar kinestetik dengan dipadukan pembelajaran 
kooperatif tipe TGT yang menuntut siswa untuk belajar dengan melibatkan fisik dapat meningkatkan hasil belajar siswa.

Mahasiswa yang memiliki kecenderungan gaya belajar unimodal hanya belajar dengan fokus pada satu jenis cara belajar saja. Sehingga diharapkan bagi pengajar dapat mengatur cara mengajar sehingga dapat sesuai untuk semua model gaya belajar mahasiswa. Gaya belajar biasa terbentuk karena kebiasaan dan biasa berubah dalam jangka waktu beberapa lama (Lisiswanti, 2014). Dengan mengetahui gaya belajar siswa maka pengajar dapat menyesuaikan model pembelajaran yang sesuai dengan kebutuhan siswa.

\section{SIMPULAN DAN SARAN}

Berdasarkan hasil penelitian tentang pengaruh penggunaan model pembelajaran kooperatif tipe TGT dan gaya belajar model VARK terhadap hasil belajar mahasiswa semester V dapat disimpulkan bahwa

1. Terdapat perbedaan hasil belajar pada pretest dan posttest mahasiswa yang diajarkan dengan pembelajaran model kooperatif tipe TGT.

2. Penggunaan model kooperatif tipe TGT memberikan pengaruh yang tinggi terhadap hasil belajar mahasiswa sebesar $45,4 \%$ pada pertemuan I dan $37,29 \%$ pada pertemuan II dengan effect size sebesar 1,69 dan 1,14.

3. Kecenderungan gaya belajar mahasiswa didominasi oleh gaya belajar kinesthetic untuk gaya belajar unimodal sebesar 44,2\% dan gaya belajar VARK untuk gaya belajar multimodal sebesar $14,7 \%$.
Berdasarkan penelitan yang telah dilakukan, saran yang dapat peneliti berikan sebagai berikut :

1. Kegiatan pembelajaran model kooperatif tipe TGT memerlukan waktu yang panjang. Sebaiknya mahasiswa sudah dikelompokkan terlebih dahulu agar waktu efisien.

2. Peneliti sebaiknya memperhatikan karakteristik siswa dan materi yang akan disampaikan agar pembelajaran tipe TGT memberikan hasil yang maksimal.

\section{UCAPAN TERIMAKASIH}

Terima kasih peneliti ucapkan kepada pihak Lembaga Penelitian dan Pengabdian pada Masyarakat Universitas Muhammadiyah Pontianak yang telah memberikan dana sehingga membantu terlaksananya penelitian ini.

\section{DAFTAR PUSTAKA}

Arikunto, S. (2010). Prosedur Penelitian: Suatu Pendekatan Praktik. Jakarta: Rineka Cipta.

Buchari, A. (2008). Guru Profesional Menguasai Metode dan Terampil Mengajar. Bandung: Alfabeta.

Desstya, A., Haryono, \& Sulistyo, S. (2012). Pembelajaran Kimia dengan Metode TGT Menggunakan Media Animasi dan Kartu Ditinjau Dari Kemampuan Memori dan Gaya Belajar Siswa. Jurnal Inkuiri, Vol. 1, No. 3, 177182.

Flemming, N. D. \& Mills, C. (1992). Not Another Inventory, 
Rather A Catalyst for Reflection. To Improve the Academy. Vol. 11, No. 246, 137-155.

Ghufron, N. \& Risnawita, R. S. (2010). Gaya Belajar Kajian Teoritik. Yogyakarta: Pustaka Belajar.

Hasrul. (2009). Pemahaman Tentang Gaya Belajar. Jurnal Medtek. Vol. 1, No. 2, 9-18.

Hawk, T. F \& Shah A. J. (2009). Using Learning Style Instruments to Enhance Student Learning. Decision Sciences Journal of Innovative Education, Vol. 5, No.1, 1-19.

Ibrahim, M. \& Nur, M. (2011). Pengajaran Berdasarkan Masalah. Surabaya: Universitas Surabaya.

Lisiswanti, R. (2014). The Relation Ship Learning Style and Student's Achievement of Lampung University Faculty of Medicine. JUKE, Vol. 4, No. 7, 6-11.
Nazir, M. (2005). Metode Penelitian. Bogor: Ghalia Indonesia

Nopiyanita, T., Haryono, \& Ashadi. (2013). Penerapan Model Pembelajaran Kooperatif Tipe Teams Games Tournament (TGT) untuk Meningkatkan Prestasi Belajar Kimia dan Kreativitas Siswa pada Materi Reaksi Redoks Kelas X Semester Genap SMA Negeri 3 Sukoharjo Tahun Pelajaran 2012/2013. Jurnal Pendidikan Kimia, Vol. 2, No. 1, 135-141.

Nufida, B. A., Muntari., \& Purwoko, A.A. (2015). Pengaruh Model Jembatan Analogi terhadap Pemahaman Aspek Mikroskopik Siswa dengan Gaya Belajar Berbeda pada Materi Pelajaran Kimia. $J$. Pijar MIPA, Vol. 8, No.1, 1622.

Slavin. R. E. (2008). Cooperative Learning. Bandung: Nusa Media. 